\title{
Evaluating of Oral Cleanliness and Gingival Health Conditions of Two Specific Groups of Workers in Karbala City
}

\author{
Sundus Mohammed Ali Al-Bazi ${ }^{1}$, Eman Kadem $^{2}$, Ala Mahdi ${ }^{3}$ \\ ${ }^{1}$ M.Sc. Student, Department of Preventive Dentistry. College of Dentistry. University of Baghdad \\ ${ }^{2}$ Assistant Professor, Department of Preventive Dentistry, College of Dentistry, University of Baghdad \\ ${ }^{3}$ Lecturer, Department of Conservative Dentistry, College of Dentistry, University of Karbala
}

\begin{abstract}
Background: Work environment has a direct effect on general as well as oral cleanness and gingival health conditions. Bakery industry deals primarily with flour which may affect the oral cleanness and gingival health conditions of workers. Aim of study: To assess and compare oral cleanness and gingival health conditions (PlI, CAlIand GI)of groups of workers producing bakery products, and control group of workers not concerned with flour. Materials and methods: Study group consisted of thirtybakery workers in Karbala city. A matching control group of thirty workers in non-production lines in the same factories were selected. Plaque index of Silness and Loe, calculus index of Ramfjord, and gingival index of Loe and Silness were used for recording oral hygiene status. Results: The finding revealed that the bakery group had higher mean values of plaque and calculus and gingivalindices than the control group with statistically non-significant differences. Conclusion: This study showed that bakery workers had higher levels of gingivitis, dental plaque and calculus. It was assumed that these findings were attributed to closer exposure of flour dust in addition to the low education.
\end{abstract}

Keywords: oral cleanness, gingival health, workers, wheat flour dust.

\section{Introduction}

The bakery industry is about making varieties of breads, cookies, cakes and pastries, and it's called, bakers confections, also called flour confections [1]. The main ingredients in this industry are wheat flour [2]. An occupation associated disease can be defined as any negative change in the health state of an individual resulting directly from persistent exposure to a harmful substance or condition related to his/her work [3,4]. Studies have shown that workers who are in regular contact with flour dust are at an increased risk of periodontal diseases, and had emphasized the need for special precautions to maintain oral health and prevent oral injuries [5,6]. This study was designed to investigates the effects of flour dust on oral hygiene status among confectionery workers in Karbala city.

\section{Materials and methods}

Sixty subjects (30 bakery workers and 30 control) in bakery factories in Karbala city included in this study. The gender depended males only, age between 21-40 years, and only employers who had spent at least 3 years in their work were included. The control group was chosen from workers not employed on production units in an environment not directly associated with flour in the same factories. All subjects had matching age, gender, work hours, education level and socioeconomic status. All the subjects were healthy with no history of serious medical problems, and were not receiving any medicaments, and not wear any fixed, removable dental prosthesis or orthodontics appliance.

Examinations were carried out in the factories in the morning, and a portable electric light source was used for illumination during examination. Each worker was seated on a chair with a tall back rest and the examiner behind worker's head. Examination was performed using a disposable plane dental mirror and explorer. A tooth was considered present in the oral cavity when any part of it was visible or could be touched by the tip of the explorer without excessively displace soft tissue. Plaque Index (Silness and Loe, 1964) system was used. The examination was started with buccal surface followed by mesial, lingual and distal surfaces of teeth examined. Dental calculus was assessed according to the calculus criteria of the periodontal disease index (PDI) by Ramfjord (1959). Gingival inflammation was assessed by using the gingival index by Loe and Silness (1963). The same teeth of the (PII) were examined and the sequence of examination was similar to the (PII).

\section{Results}

Table (1) illustrates the mean values and standarddeviations of plaque index in bakery group higher than control group $(0.839 \pm 0.064, \quad 0.702 \pm 0.062$ respectively) with nonsignificant difference ( $p>0.05)$, and for calculus index the mean values and standard deviation for bakery group higher than control group $(0.295 \pm 0.056,0.123 \pm 0.026$ respectively) with non-significant difference $(\mathrm{p}>0.05)$. Table (2) shows the mean values and standard deviations of gingival index for bakery group higher than control group $(.491 \pm .065, .327 \pm .059$ respectively) with non-significant difference $(\mathrm{p}>0.05)$. 


\section{International Journal of Science and Research (IJSR) \\ ISSN (Online): 2319-7064}

Index Copernicus Value (2016): 79.57 | Impact Factor (2015): 6.391

Table 1: Descriptive and statistical test of oral health cleanliness among group

\begin{tabular}{|c|c|c|c|c|c|c|}
\hline Variables & Groups & Mean & \pm SE & F & df & P-value \\
\hline \multirow{4}{*}{ PLI } & Control & 0.702 & 0.062 & \multirow{2}{*}{2.227} & & 0.089 \\
& Bakery & 0.839 & 0.064 & & & NS \\
\cline { 2 - 5 } \cline { 2 - 3 } & Total & 0.811 & 0.030 & & \\
\hline \multirow{4}{*}{ CAL } & Control & 0.123 & 0.026 & \multirow{2}{*}{2.079} & & $\begin{array}{c}0.107 \\
\text { NS }\end{array}$ \\
\cline { 2 - 4 } \cline { 3 - 4 } & Bakery & 0.295 & 0.056 & & \\
\cline { 2 - 4 } & Total & 0.224 & 0.025 & & \\
\hline
\end{tabular}

$\mathrm{NS}=$ Not significant at $\mathrm{P}>0.0$

Table 2: Descriptive and statistical test of GI among groups

\begin{tabular}{|c|c|c|c|c|c|}
\hline Groups & Mean & \pm SE & F & df & P-value \\
\hline Control & .327 & .059 & & & 0.078 \\
Bakery & .491 & .065 & 5.055 & \multirow{3}{*}{3} & NS \\
\cline { 1 - 3 } \cline { 1 - 2 } Total & .460 & .031 & & & \\
\hline
\end{tabular}

$\mathrm{NS}=$ highly significant at $\mathrm{P}>0.05$

The distribution of the gingival inflammation according to the severity is shown in Table (3). The prevalence of gingivitis was $92.5 \%$ in both bakery and control groups. Mild gingivitis was the most prevalent type among the bakery and control groups, whereas in both groups no severe gingivitis case was recorded.

Table 3: Distributions of gingival inflammation according to severity between groups

\begin{tabular}{|c|c|c|c|c|}
\hline \multirow{2}{*}{ Groups } & & \multicolumn{3}{|c|}{ GI severity } \\
\cline { 3 - 5 } & & Healthy & Mild & Moderate \\
\hline \multirow{4}{*}{ Control } & NO. & 6 & 22 & 2 \\
\cline { 2 - 5 } & \% GI & 66.67 & 21.15 & 28.57 \\
\cline { 2 - 5 } & $\%$ groups & 20.00 & 73.33 & 6.67 \\
\cline { 2 - 5 } & $\% \mathrm{~T}$ & 5.00 & 18.33 & 1.67 \\
\hline \multirow{4}{*}{ Bakery } & NO. & 3 & 25 & 2 \\
\cline { 2 - 5 } & \% GI & 33.33 & 24.04 & 28.57 \\
\cline { 2 - 5 } & \% groups & 10.00 & 83.33 & 6.67 \\
\cline { 2 - 5 } & $\% \mathrm{~T}$ & 2.50 & 20.83 & 1.67 \\
\hline \multirow{4}{*}{ Total } & NO. & 9 & 104 & 7 \\
\cline { 2 - 5 } & \% GI & 100.00 & 100.00 & 100.00 \\
\cline { 2 - 5 } & $\%$ groups & 7.50 & 86.67 & 5.83 \\
\cline { 2 - 5 } & $\% \mathrm{~T}$ & 7.50 & 86.67 & 5.83 \\
\hline
\end{tabular}

\section{Discussion}

The present study revealed higher mean values of plaque and calculus indices in bakery workers than control group, however the difference was statistically non-significant. It is assumed that workers usually neglect oral care measures during working hours $[7,8]$ therefore plaque and deposits accumulate on their teeth. In this study, the levels of plaque and calculus of the bakery groupwere higher than those of control group, and these differences between them could be explained by accumulation of more plaque induced by high level of flour dust $[6,9,10]$.Similarly, bakery workers had insignificantly higher levels of gingivitis. Similar findings were reported byBachanek5,6 who evaluated the dental health status of mill workers and stated that they have more gingivitis than a control group. While Masalin9 stated thatthere was no statistically significant difference regarding periodontal status between bakery and control groups in Finland.This disagreement could be attributed to the work hygiene measurements followed among the Finish population. The higher levels of gingival inflammation revealed in this study reflect the fact that dental diseases in general are very common among workers. Gingivitis is a nonspecific inflammatory response to dental plaque around the gingival margin [11,12]. This may explain the $86 \%$ of gingivitis recorded in all groups.Another explanation for the higher mean value of gingival index among bakery group than the control group may be presented by the fact that foods with a higher content of flour were cleared slower from the mouth than other types of food contents [10].

\section{References}

[1] Dictionary of Food Science and Technology,2009 (2nd ed.). Chichester, U.K.: Wiley-Blackwell: 106.

[2] GisslenW. 2013.Professional baking. John Wiley \& Sons, Inc., Hoboken, New Jersey.

[3] Petersen PE. 1989. Evaluation of a dental preventive program for Danish chocolate workers. Community Dent Oral Epidemiol, 17:53-59

[4] Gueorguieva R, SindelarJl, Falba Ta, Fletcher M, Keenan P, Wu R, Gallo WT. 2009. The Impact of Occupation on Self-Rated Health: Cross-Sectional and Longitudinal Evidence from the Health and Retirement Survey. J Gerontol B Psychol Sci Soc Sci, 64B(1):11824.

[5] Bachanek T, Pawłowicz A, Tarczydło B, Chalas R.2001. Evaluation of dental health in mill workers. Part I. The state of dentition.Ann Agric Environ Med. 2001;8(1):103-5.

[6] Bachanek T, Chalas R, Tarczydlo B, PawlowicZA. 2003. Evaluation of millers' dental health. Part II. State of the parodontium.Ann Agric Environ Med, 10(2):2579.

[7] Petersen PE. 1983. Dental health among workers at a Danish chocolate factory. Community Dent Oral Epidemiol, 11(6):337-41.

[8] Bansal M, Veeresha K1. 2013. Oral health status and treatment needs among factory employees in Baddi-Barotiwala-Nalagarh Industrial hub, Himachal Pradesh, India. Ind J Oral Sci, 4(3):105-9.

[9] Masalin K, Murtomaa H, Meurman JH 1990. Oral health of workers in the modern Finnish confectionery industry. Community Dent Oral Epidemiol, 18(3):12630.

[10] Bibby BG, Mundorff SA, Zero DT, AlmekinderKJ. 1986. Oral food clearance and the $\mathrm{pH}$ of plaque and saliva. J Am Dent Assoc, 112(3):333-7.

[11] Falco MA. 2001. The life time impact of sugar excess and nutrient depletion on oral health. Gen Dent, 49(6):591-5.

[12] HaakeS. 2002. Etiology of periodontal disease, in: Newman M, Taki H, Carranza F. Carranza's clinical periodontology, part 3, Saunders Elsevier, china. 